\title{
MULHERES ESCRITORAS EM DIFERENTES ESFERAS DISCURSIVAS
}

\author{
ANÁLISE SOBRE O OLHAR DO OUTRO POR MEIO DA CÂMERA \\ E SOBRE A AUTORREPRESENTAÇÃO REALIZADA PELA \\ ESCRITA
}

\author{
WOMEN WRITERS IN DIFFERENT DISCURSIVE SPHERES \\ ANALYSIS ABOUT THE LOOK OF THE OTHER THROUGH THE \\ CAMERA AND THE SELF-REPRESENTATION PERFORMED BY \\ WRITING
}

\author{
NATHALIA BARBOSA* \\ nathaliafobarbosa@gmail.com
}

Pensando no papel da fotografia na construção e reforço de múltiplos discursos, este artigo busca expandir a análise de Walter Benjamin em Pequena história da fotografia sobre a foto de atelier do escritor Franz Kafka.

A consideração sobre o olhar triste e desolado de Kafka contrastando com o cenário planejado, para proporcionar uma imagem de aura luxuosa e enfeitada, trouxe um questionamento ampliado que este artigo busca responder: analisando pessoas que escreveram sobre si mesmas, quais são os pontos de contato e de divergência entre autorrepresentação por meio da escrita e pelo olhar dos outros por meio da câmera e das fotografias?

Por ser de caráter ainda obscuro, o foco da investigação são autoras de diferentes épocas com estilos distintos entre si: Anne Frank e suas fotografias familiares, Sylvia Plath e o estabelecimento de um ideal feminino por meio das aparências e, por fim, a artista punk Patti Smith e os Estados Unidos como cenário mutável e de "refugo". Para discorrer sobre os relatos dessas mulheres sobre si mesmas e suas imagens estabelecidas na história, este artigo recorre aos ensaios de Susan Sontag, relacionando fotografia, contexto histórico e literatura.

Palavras-Chave: fotografia; literatura; representação; autorrepresentação; mulheres.

Thinking about the photos' role in the construction and reinforcement of multiple discourses, this article aims to expand the analysis of Walter Benjamin in A Small History of Photography on the atelier's portrait of the writer Franz Kafka.

The consideration about the sad and desolated Kafka's look contrasting with the planned scene to provide an image of a luxury and embellished aura bring an amplified question which this article searches to answer: thinking about people that wrote about themselves, what are the points of contact and divergence between the self-representation through the writing and through the look of the other by the camera and the photographs?

Because its character is still obscure, the focus of the investigation comes from different eras with different styles: Anne Frank and her family photos, Sylvia Plath and the establishment

\footnotetext{
* Mestranda, Sorbonne Université, Faculté des Lettres, Institut d'études hispaniques, Paris, França. ORCID: 0000-0003-1371-3280
} 
122 NATHALIA BARBOSA

of a feminine ideal based on appearances and, finally, the punk artist Patti Smith and the United States as changing and "scrap" scenario. In order to discuss these women's reports about themselves and their images established in history, this article has recourse to Susan Sontag's essays, relating photography, historical context and literature.

Keywords: photography; literature; representation; self-representation; women.

Data de receção: 18-03-2021

Data de aceitação: 01-09-2021

DOI: $10.21814 / 2 \mathrm{i} .3362$ 


\begin{abstract}
És; mais ou menos como, por exemplo, um autocrata que, quando está fora dos limites de seu país, não tem motivo para continuar sendo tirânico e pode mostrar-se bondoso em relação com as pessoas da mais baixa condição social. E isso se confirma, por exemplo, vendo as fotografias de conjunto de

Franzensbad, onde sempre apareces tão grande e alegre entre as pessoas pequenas e toscas, como um rei que está empreendendo um passeio.
\end{abstract}

- Franz Kafka

\title{
1. Introdução
}

É quase impossível discorrer sobre algum campo da fotografia sem mencionar os estudos de Walter Benjamin sobre a influência das imagens, da reprodução, e da perda da aura de obras de arte proporcionadas pela foto.

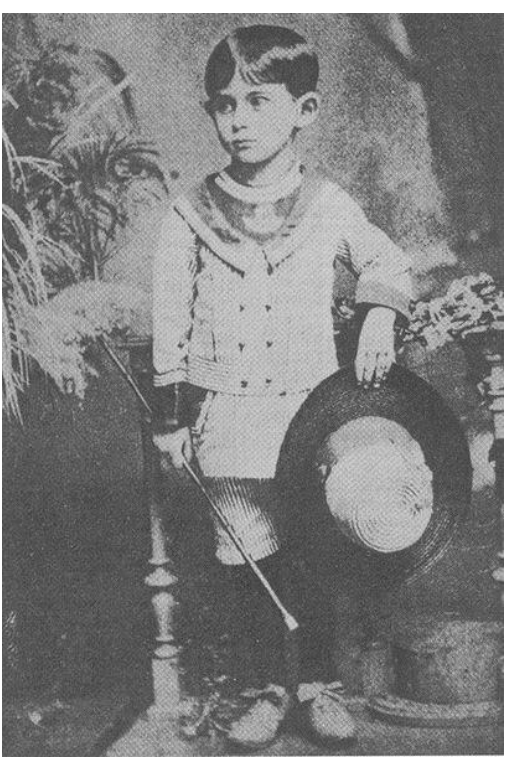

Fig. 1 Autor desconhecido (1887)

Porém, desvirtuando das questões costumeiras que ocupam o centro da discussão, como a argumentação técnica, os impasses entre a pintura e a fotografia, imitação ou superação da realidade, este artigo tangencia tal caminho ao realizar uma leve divergência. A ideia ocorreu a partir de Pequena história da fotografia, ensaio no qual Benjamin, para exemplificar os primeiros retratos que ocupavam os álbuns de família, descreve o daguerreótipo do escritor tcheco Franz Kafka. Chama a atenção o prenúncio estampado no rosto de uma criança de 6 anos sobre o que seria sua obra no futuro, desbancando a intenção do retrato de enaltecer uma abundância econômica alcançada: uma literatura do absurdo empenhada em criticar o avanço técnico-industrial e a indiferença instaurada entre as classes sociais.

Nos primórdios da fotografia, os modelos eram obrigados a ficar imóveis por um longo tempo devido à expressiva duração de exposição exigida pela câmera, de modo que "os fotógrafos se contentavam com dispositivos para fixar a cabeça ou o joelho. Depois vieram outros acessórios" (Benjamin, 2012, p. 98). Nesse estilo, Benjamin ressalta que, no meio de tantos adornos para deixarem o resultado "artístico", como chapéus, palmeiras, colunas sobre o tapete e roupas de rendas, os olhos do menino Kafka, tristes e desolados, dominam a paisagem e evitam que o mesmo desapareça no quadro. Portanto, eles podem ser considerados uma espécie de resistência àquilo que não condiz com a sua personalidade ocupando $o$ entorno e a lente.

A contradição entre o esforço de transmitir elegância por meio da fotografia possivelmente partindo da vontade dos pais do escritor -, e a personalidade daquele que conhecemos como avesso à proposta da fotografia colocada em prática, símbolo do progresso técnico e elemento de ostentação da burguesia, leva-nos à questão entre o objetivo de representação por parte do fotógrafo e a autorrepresentação possibilitada por meio da escrita do tema que toma posse da descrição de si mesmo, inventando a legenda de sua própria imagem. Indo além da discussão que evoca polêmicas sobre a importância da fotografia em detrimento da legenda e vice-versa, este artigo tem como 
objetivo focar em um grupo que, mesmo passados quase dois séculos desde o surgimento da invenção de Daguerre, ainda sofre com dificuldades de ter sua justa expressão nos diferentes tipos de mídias. Tal grupo é composto por mulheres.

Subvertendo a lógica de fotografia apenas comercial, exaltando modelos próximas à satisfação do julgamento determinando do que é "belo", este texto traz à luz análises sobre a projeção de mulheres escritoras sobre si mesmas e como suas descrições íntimas interagem - ou refutam - suas representações fotográficas. Considerando os padrões impostos de aproximação à feminilidade ideal, destituindo as mulheres da expressão de uma verdadeira personalidade em detrimento do uso de seus corpos como meros objetos de fetiche e comercialização, a câmera, ao transmitir uma visão que o Spectrum (feminino) não tem de si mesmo, reforça a violência física e moral cometida contra tal gênero. Seguindo o feito de Kafka ao desmontar um quadro cuidadosamente arranjado de fotografia, recorro a mulheres que, assim como ele, tiveram essa mesma oportunidade por meio da escrita - e a exploraram com tamanha potência -, construindo, ao longo do século XX e XXI, perfis fortes, para além das aparências idealizadas, com seus relatos autobiográficos e de resistência.

\section{O papel das fotografias familiares n' O Diário de Anne Frank}

Coincidentemente, a primeira mulher, ou melhor, menina a ocupar o início deste estudo lutou e teve seu fim trágico no local que estampa as fotos responsáveis por uma grande mudança na vida da crítica fotográfica Susan Sontag, como relatado no ensaio $\mathrm{Na}$ caverna de Platão. Trata-se do campo de concentração de Bergen-Belsen, no qual Anne Frank, autora do relato mais popular sobre a Segunda Guerra Mundial, faleceu.

Sem haver imagens dos últimos dias de Anne Frank, tirando algumas suposições imagéticas encontradas na internet, o que vemos publicado nas inúmeras edições de seu diário são fotografias de álbuns de família e do casamento de Jan e Miep Gieps, ajudantes responsáveis pela manutenção e proteção das famílias Frank e Van Daan no anexo secreto.

Muitas pessoas - próximas ou não de Anne -, que viram as fotos, podem ter a primeira impressão de uma garota feliz, sempre animada, sem se preocupar muito com os problemas à sua volta, como ela mesma declara: "penso em mim como uma pessoa feliz por dentro, e os outros pensam que sou feliz por fora." (Frank, 2016, p. 403). Seus sorrisos podem ser interpretados como uma representação frente ao aparelho fotográfico, como Benjamin destaca ocorrer a ação do intérprete se relacionando com a reprodução cinematográfica. Porém, tal definição não basta, considerando que esses registros pré e durante a guerra adquiriram uma importância histórica superior a um consumo massificante e alienado e, no contexto no qual foram concebidos, superior à importância de compor as memórias familiares. Eles não foram feitos, pois, com o propósito de ampla reprodução ao redor do mundo, mas com os relatos que envolvem as pessoas que aparecem nas fotografias, tornaram-se de fácil acesso a quem deseja estudar suas narrativas de vida envoltas por um contexto específico.

A proeza das fotos de Anne Frank e de todos que conviveram no Anexo Secreto durante a invasão alemã à Holanda, na verdade, é uma prova que aquilo aconteceu e tais foram possibilitadas graças ao costume dos pais de fotografarem seus filhos, pois "não tirar fotos dos filhos, sobretudo quando pequenos, é sinal de indiferença paterna" (Sontag, 2004, p. 19). Seguindo a tese de Sontag ao afirmar que a fotografia democratiza as experiências ao traduzi-las em imagens, sua função é pertinente para confirmar a veracidade não só do Holocausto, como, também, a sagacidade de uma 
menina de 15 anos capaz de superar a criminalização dos judeus por meio de suas palavras, uma vez que as imagens fotográficas ocupam o espaço de maior autoridade na sociedade moderna ao representarem uma máscara mortuária, um vestígio da realidade e da vida de alguém (Sontag, 2004, pp. 26, 85).

Pode-se dizer que o principal propósito da reunião de fotos dos judeus mortos no Holocausto é ser, além de um testemunho histórico, também uma nostalgia de alívio. As imagens de parentes e amigos mortos - neste caso, reunidas pelo pai Otto Frank -, preservadas pelo álbum de família, "exorciza uma parte da angústia e do remorso inspirados por seu desaparecimento" (Sontag, 2004, p. 26); mas, uma vez que o álbum de família é reproduzido em longa escala, assume concomitantemente a função de alimentar o imaginário popular. $\mathrm{O}$ que poderia ter acontecido àquelas pessoas caso elas existissem no presente para além do vestígio do passado?

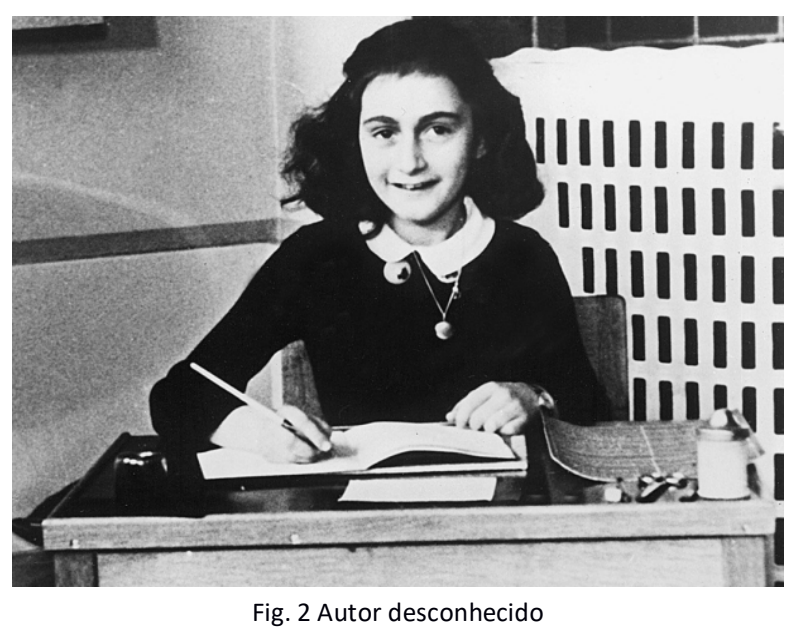

Muitas das fotos de Anne Frank mostram-na escrevendo ou junto de cadernos para anotações. Talvez esses sejam seus registros mais fiéis e próximos de sua representação de futuro, caso seus desejos fossem realizados: ser jornalista e escritora. A memória social evocada por fotos e legendas - estas que foram feitas a partir dos próprios relatos da autora - não só confere veracidade aos seus escritos de uma figura que, por vezes, foi vista com descredibilidade em vida, por seus parentes, e pós-morte, por críticos a seu diário, colocando em questão sua capacidade de transmitir uma interpretação de um contexto histórico conturbado do século XX. Como não associar uma menina de 11 anos, em posição ereta, que encara a câmera frontalmente com a mão apoiada na mesa, segurando uma caneta, ao arquétipo de um jornalista que aparece na televisão para nos informar sobre os acontecimentos diários e globais? Ou ainda, como duvidar dos relatos de um diário de alguém que muitas vezes fora fotografada escrevendo?

Com os próprios escritos de Anne, percebe-se a resistência por parte dos adultos na aceitação da opinião de uma figura feminina e de idade jovial. Mas as próprias fotografias atreladas ao diário da autora quebram, por gerações, e continuarão a quebrar, o mito de uma criança fútil, uma mulher sem opinião ou embasamento político. Assim sendo, seu diário é um dos relatos jornalísticos mais pertinentes de todos os tempos, fazendo jus à sua autodescrição e enfrentando a despersonificação feminina, mesmo com sua morte prematura:

Sei o que quero, tenho um objetivo, tenho opiniões, uma religião e amor. Se ao menos eu pudesse ser eu mesma, ficaria satisfeita. Sei que sou uma mulher, uma mulher com força interior e muita coragem!

Se Deus me deixar viver, vou realizar mais do que mamãe jamais realizou, vou fazer com que minha voz seja ouvida, vou para o mundo e trabalharei em prol da humanidade! (Frank, 2016, p. 320)

\section{O ideal imagético feminino na vida de Sylvia Plath}


A maior parte do desejo por um ideal feminino é alimentada por revistas de moda e anúncios publicitários. Apesar da recente mudança nesses campos, reivindicando mais diversidade nas representações femininas, ainda há uma ampla barreira a ser superada, e nem sempre os anseios sociais mudam, como, por exempo, um corpo esbelto, cabelo liso, uma bolsa de estudos, uma vaga no editorial de uma importante revista de moda e um pedido de casamento realizado por um estudante de medicina. O que parece ser a descrição do sonho de uma mulher é um breve resumo de uma época da vida de Sylvia Plath, importante poeta estadunidense, conhecida pelo romance $A$ redoma de vidro, obra publicada pouco antes de seu suicídio.

Sob o pseudônimo de Esther Greenwood, Sylvia escreveu sua constante batalha para se afirmar como uma mulher competente e independente, apesar de sua depressão e inserção no contexto pré-revolução sexual. Quando Sontag compara seu sucesso póstumo com o da fotógrafa Diane Arbus, relacionando as qualidades "sincera", "compassiva" e "não fria" à obra desta última, o contraste entre os adjetivos atribuídos implicitamente à obra de Sylvia não parece justo, afirmando ainda que o sucesso alcançado por Arbus pós-morte "é de outra ordem - uma espécie de apoteose" (Sontag, 2004, p. 51).

O sucesso alcançado por Sylvia Plath pós-morte é também uma apoteose à medida que sua afirmação como mulher sã, ${ }^{2}$ apesar da internação, e crítica em relação à situação influenciada por uma era pós-guerra em que vivia fica cada vez mais evidente em suas obras. Ela escreve sobre seus planos e desejos, de maneira perspicaz do início ao fim de sua jornada, quando poderia ser mais conveniente a volta da mulher ao ambiente doméstico:

Ansiar por um organismo do sexo oposto que compreenda e eleve seus pensamentos e instintos, e se dar conta de que a maioria dos machos americanos endeusam a mulher como máquina sexual de peitos fartos e conveniente abertura na vagina, uma boneca pintada que não deve ter na cabecinha linda outro pensamento além de preparar um filé para o jantar e agradá-lo na cama após a rotina diária de trabalho duro, das nove às cinco. (Plath, 2017, p.51)

Seu suicídio, portanto, parece uma metáfora à máxima bíblica de deus como "o alfa e o ômega", um ser eterno, com o final de sua vida iniciando tantas discussões sobre uma mulher escritora, que foi extremamente determinada em fornecer um retrato de sua trajetória por meio das letras. Apesar de não conseguir controlar a situação na qual se encontrava, suas denúncias sobre misóginia e pressão exercida pela sociedade, pelo ambiente acadêmico, profissional e pelo padrão de beleza imposto servem como caminho de salvação para outras tantas mulheres que vieram a conhecer sua obra inspiradora que defende o ideal da mulher como dona de si mesma.

O principal ponto de diferença entre o objetivo da obra de Arbus e o de Plath talvez seja o posicionamento das duas quanto o objeto de exposição. Enquanto Arbus possui um controle da cena ao assumir a construção da representação por meio da lente, dando-lhe uma liberdade e justificativa para "ir aonde quisesse e fazer o que desejasse" (Sontag, 2004, p.54), Plath é justamente a caça do gatilho da câmera, vítima da violência daquele que tem uma visão a qual o tema da foto não terá de si mesmo como exemplifica a autora ao descrever sua experiência traumática em um ensaio editorial:

\footnotetext{
${ }^{2}$ Neste ponto, há uma pequena confusão relacionada à cronologia da obra da escritora. Apesar de $A$ redoma de vidro ter sido lançado com sucesso pouco antes de seu suicídio, o romance, junto à coletânea de poesias Ariel, pode ser considerado como sucesso póstumo uma vez que seu caráter autobiográfico vem à tona, sem dúvidas, quando a morte de Sylvia confirma sua depressão relatada por meio da construção de Esther.
} 
Quando levantei a cabeça, o fotógrafo tinha desaparecido, assim como Jota Cê. Me senti frágil e traída, como a pele que um animal terrível deixa para trás. Era um alívio ter me livrado do animal, mas parecia que ele tinha levado consigo o meu espírito e tudo o que suas patas conseguiram agarrar. (Plath, 2019, p. 116)

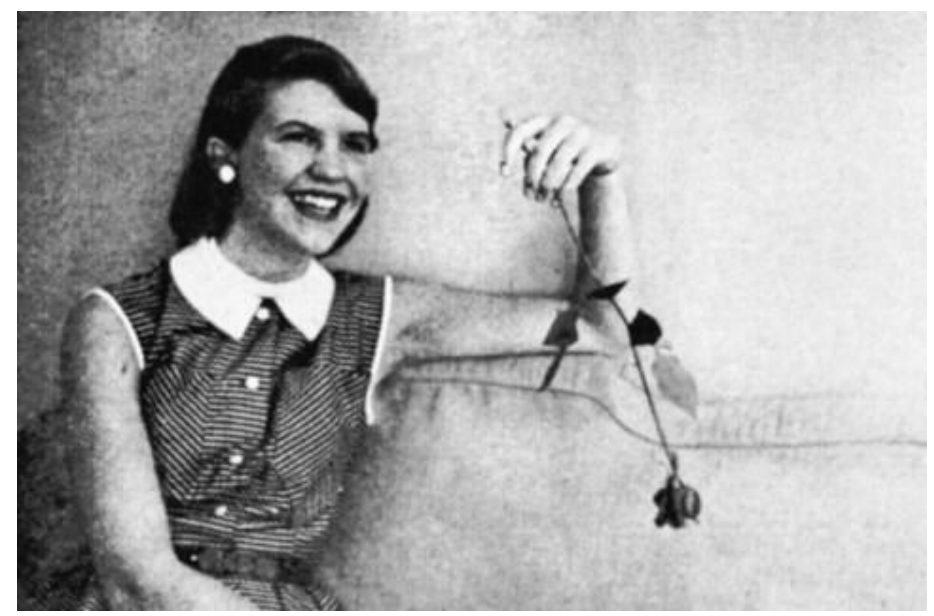

Fig. 3 Autor desconhecido, Foto para Revista Mademoiselle (1953)

O objetivo do ensaio era fotografar as representantes da revista com algo que remetesse a suas paixões e a seus desejos. Sylvia seguraria uma rosa para combinar com o tom lírico da poesia que almejava. A comparação do fotógrafo com o animal podendo ser entendido como um animal de caça em busca de sua presa - revela a incapacidade de representar satisfatoriamente a autora e a violência ao impor uma visão que ela não tinha sobre si mesma. Sua afirmação em $A$ redoma de vidro vai ao encontro da ideia de que "o pavor primitivo das câmeras que decorre de pensar a foto como uma parte material delas mesmas" (Sontag, 2004, p. 177), dá ao ato de fotografar uma possibilidade de aquisição, a "posse vicária de uma pessoa de uma coisa querida" (Sontag, 2004, p. 172):

Existe algo de predatório. Fotografar pessoas é violá-las, ao vê-las como elas nunca se veem, ao ter delas um conhecimento que elas nunca podem ter; transforma as pessoas em objetos que podem ser simbolicamente possuídos. Assim como a câmera é uma sublimação da arma, fotografar alguém é um assassinato sublimado - um assassinato brando, adequando a uma época triste e assustada. (Sontag, 2004, p. 25)

A realização do enquadramento representaria a podagem da rosa que a autora segurava e dela mesma, reduzida a uma imagem idealizada por uma revista feminina e dominada pela câmera, manuseada por um homem.

Ao contrário dos temas de Arbus, que encaram a lente apesar das "imperfeições" que carregam, fazendo da própria imagem um objeto invasivo e contestador do conceito de belo, Sylvia se esconde da imagem - que por muitas vezes a oprimiu - para fazer da legenda, em forma de livros, seu retrato mais conciso. Afirma, apesar das adversidades e classificações sofridas, "eu sou, eu sou, eu sou" até seus últimos dias, alcançado seu desejo de ser uma poeta citada em outras épocas que não suas. Sylvia Plath é, para além da beleza mostrada nas fotos, uma mulher, como várias, de opinião e personalidade para além de um mero objeto publicitário e idealizado conforme os anseios da sociedade composta por uma hierarquia misógina e predatória. Sua recusa perante a câmera revela, portanto, um de seus medos de dominação que escrevera em seu diário: 
Então ele me acusa de "querer dominar"? Desculpe, foi engano. Claro, sinto um certo medo de ser dominada. (Quem não sente? Só os indivíduos do tipo submisso, dócil, meigo. E eu Não sou assim, Não sou.) (Plath, 2017, p. 128).

\section{O cenário de Patti Smith: os Estados Unidos de refugo}

Ao contrário das figuras supracitadas, Patti Smith, mulher símbolo do movimento Punk, costuma ser retratada pela mídia como ousada e desordeira. Suas fotos, entre as quais muitas foram tiradas no famoso clube de encontro para adeptos e artistas do rock, o CBGB, normalmente são de queixo arqueado, braços abertos, expressão de grito, cabelo bagunçado, como alguém que está à vontade em ocupar todo o espaço e ter todo o seu respectivo controle.

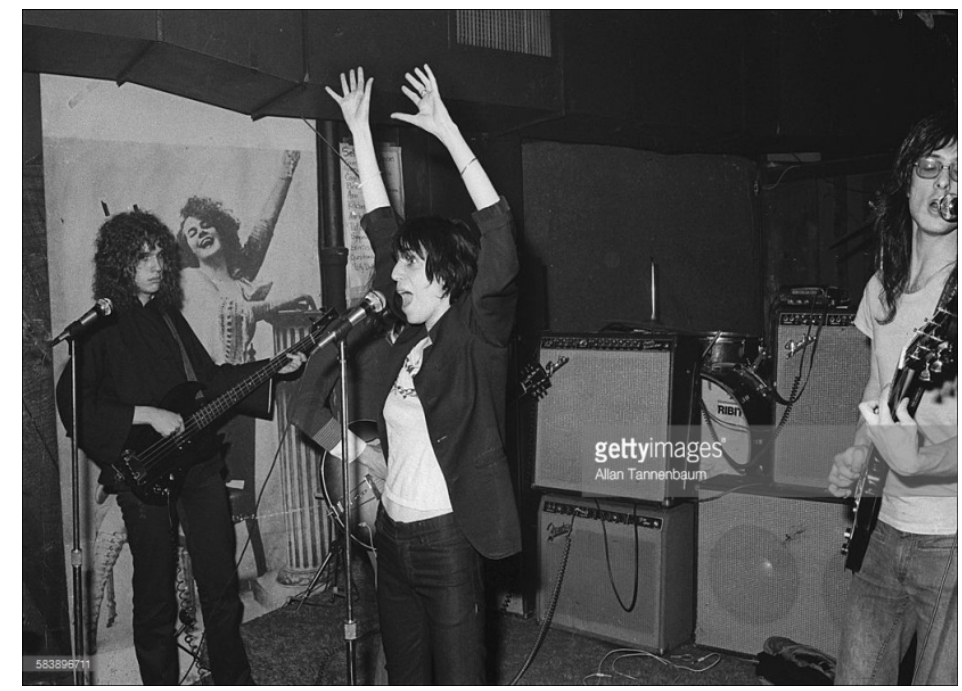

Fig. 4 Alla Tannenbaum, Patti Smith Hands Up CBGB (1975)

Porém, em contraste com essa figura rebelde a qual acostuma-se ver em documentários sobre a história do rock, Patti Smith é uma escritora de extrema sensibilidade - muitas vezes, de fala mansa e doce ao dar uma entrevista ou conversar com alguém -, remetendo ao romantismo europeu, inspirada principalmente pela obra de Arthur Rimbaud e pelo espírito desbravador de Joana D'Arc.

Criada em Nova Jersey e de família humilde, Patti partiu para Nova York pretendendo sobreviver somente a partir da arte. Com 20 anos, conheceu Robert Mapplethorpe, fotógrafo pioneiro em explorar a revolução sexual dos anos 60/70 a partir do viés LGBT. Passou, então, a morar com o futuro fotógrafo no Hotel Chelsea, lugar que reuniu diversos artistas, como Salvador Dalí e Diane Arbus. O aluguel poderia ser pago com produções artísticas, incluindo a fotografia. O resultado da câmera naquele local levou ao extremo a possibilidade de "exprimir a impaciência americana com a realidade, o gosto por atividades cujo instrumento é uma máquina" (Sontag, 2004, p. 79) e, em meio às caixas de som tocando Jefferson Airplane e John Lennon, Mapplethorpe eternizou o cenário e o sentimento de tal fase por meio das fotos de Patti pelas ruas e na suíte onde moravam:

Naquela noite, excitada demais para dormir, um infinito de possibilidades pareceu rodopiar sobre mim. Fiquei olhando para o teto de gesso como fazia quando era criança. Foi como se os padrões vibracionais acima de mim mudassem de lugar até se encaixarem todos (Smith, 2010, p. 104). 
A mutabilidade característica dos Estados Unidos, com um tom misterioso e a possibilidade de qualquer detalhe virar relíquia, consequência da rápida obsolescência, fez com que até mesmo as fotos de Patti pelas ruas - sem nenhuma superprodução virassem uma documentação fiel de uma época revolucionária. Apesar disso, o contraste entre a tradição europeia, com a estabilidade da natureza e de inúmeras tradições literárias preservadas, e a efervescência selvagem de Nova York instiga a cantora a viajar para Paris em busca dos vestígios dos autores clássicos, com suas obras e residências preservadas pelos museus e pela arquitetura da cidade.

Quando Fred, ex-marido de Patti, afirma ao olhar para uma foto destinada ao compacto People Have the Power que Mapplethorpe, responsável pela mesma, confunde-se com Patti, há uma possibilidade de discordância quanto à interpretação. É quase impossível olhar para Patti sem relacioná-la com o gosto pelo romantismo do século XIX, enquanto Bob, com suas fotos em preto e branco e de caráter sadomasoquista, está de acordo com o progresso impulsionado pela revolução sexual e considera a realidade de seu país estupenda, como observa Sontag ao analisar os sentimentos dos fotógrafos estadunidenses.

Patti, ao contrário, revela-se como uma trovadora por meio da música e de suas fotos com fundo neutro - e até pássaros -, apegando-se à tradição romântica da Europa, como repete inúmeras vezes em Só garotos. Seus relatos de menina que deu seu filho para alguém por falta de condições favoráveis, de mulher que percorreu a França em busca de vestígios de Arthur Rimbaud, e que fora traída inúmeras vezes, sem abandonar o afeto por seus amantes, contradizem quase todas suas fotos no palco e apregoadas nos diversos informativos midiáticos sobre rock. Por outro lado, a fotografia de sua intimidade revela alguém paciente tentando se adaptar ao turbilhão de mudanças dos Estados Unidos na década de 70.

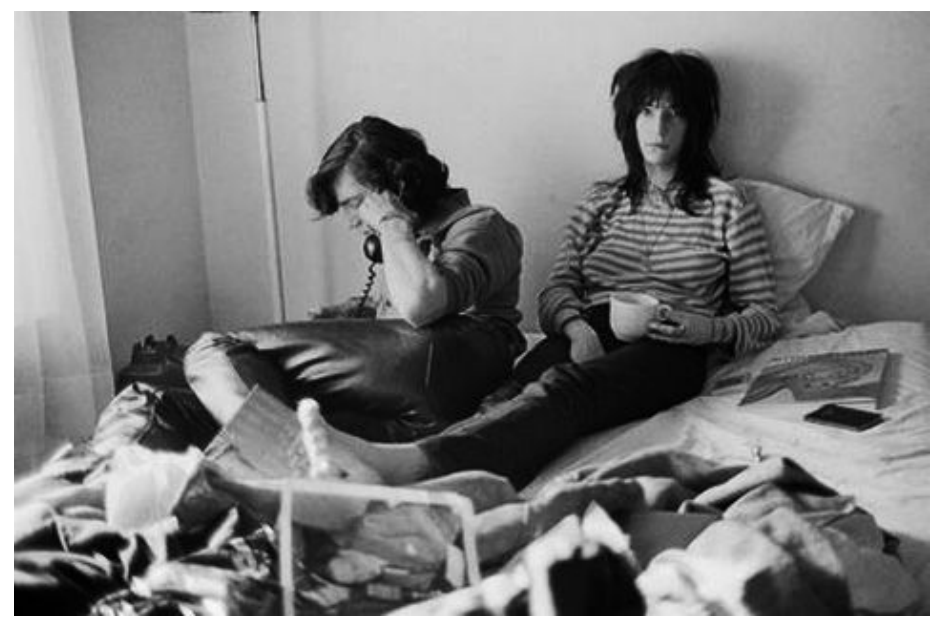

Fig. 5 Judy Linn, Hotel Chelsea, quarto 204 (1970)

De fato, não é Patti que fica parecida com Mapplethorpe nas fotos; o imaginário apenas tenta descrevê-la por meio da figura de um homem. Tal classificação não define satisfatoriamente a fusão entre o Punk e o Romantismo presente tão excêntricamente na figura de Patti Smith. O julgamento demonstra um distanciamento da autenticidade de uma mulher, enquanto há ora a revelação de uma realidade mais íntima frente à câmera de seu companheiro, ora há fotos de êxtase no palco. Mas, em todos os casos, parece ainda predominar a submissão de um tema feminino mantida por um homem, ou um anseio comercial apelativo que controla o enquadramento da foto; mais tarde, a indústria do rock preza pela rebeldia apenas como fator comercial, muitas vezes 
vendendo imagens em detrimento de ideais, canções e personalidades de complexidade formada para além de interesses monetários e imagens estrategicamente divulgadas:

Nós nos víamos como os Filhos da Liberdade com uma missão de preservar, proteger e projetar o espírito revolucionário do rock and roll. Temíamos que a música que sempre nos sustentara estivesse correndo o risco de subnutrição espiritual. Temíamos que perdesse seu propósito, temíamos que caísse em mãos aburguesadas, temíamos que patinasse no lodo do espetáculo, das finanças e da complexidade técnica insossa. Vinha-nos a lembrança da imagem de Paul Revere, cavalgando pela noite americana, acordando as pessoas, incitando a que pegassem em armas. Nós também pegaríamos em armas, as armas da nossa geração, a guitarra elétrica e o microfone. (Smith, 2010, p. 224).

Enquanto isso, por meio de sua produção literária, Patti muda o julgamento dos olhares lançados e fixados sobre ela ao recontar, com as próprias palavras, sua trajetória artística, que permanece até hoje com bases sólidas do passado, ao contrário das ruas de Nova York em constante mudança, com vestígios impressos somente em fotografias e relatos de quem viveu outras épocas a andar sobre suas calçadas.

\section{Considerações finais}

As escolhas realizadas pelos fotógrafos, muitas vezes, reduzem a imagem da mulher a mero interesse comercial e publicitário, buscando um conceito normatizante do que é "belo". Porém, é possível perceber que o relato de muitas, compondo uma extensa legenda, possibilita o lugar de fala como uma expressão autêntica de personalidade e opinião para além da imagem utilizada em diversos contextos - históricos, sociais e artísticos - e com objetivos originais variados.

Nesse caminho, o contexto histórico demonstrou ser crucial para entender o impacto da autorrepresentação de cada mulher por meio da literatura. Percebe-se que as obras escritas esclarecem as suas imagens divulgadas ao expandirem a interpretação da realidade, contrariando o domínio de quem detém o controle da lente.

Em todos os casos, a afirmação de pensamentos subverte - ou tenta subverter - uma hierarquia dominada pelo olhar familiar, masculino e comercial. O resultado, pois, são incentivos à afirmação das mulheres como detentoras de opiniões e interpretações pertinentes ao longo das gerações, levando ao extremo a máxima de Sylvia Plath ao se considerar como alguém de personalidade: "Eu sou, eu sou, eu sou".

Tal falta de representatividade pode ser explicada pelo delay das mulheres em assumirem o lugar decisivo por trás das câmeras, explicado, por parte, pela falta de acessibilidade aos equipamentos. Atualmente, organizações e ações são desenvolvidas a fim de solucionar a falta de representatividade feminina na fotografia. Um dos clássicos na área é Women, um ensaio fotográfico realizado por Annie Leibovitz e Susan Sontag com mulheres de diversas classes, etnias e profissões. Enquanto o aparato técnico ainda está no campo de atraso, a literatura serve como legenda esclarecedora de realidades encontradas em forma de vestígios imagéticos da sociedade moderna.

\section{REFERÊNCIAS}

Benjamin, W. (2012). História da fotografia. In Obras escolhidas vol. 1: Magia e Técnica, Arte e Política. Ensaios Sobre Literatura e História da Cultura (pp. 91-107). São Paulo: Editora Brasiliense.

Frank, A. (2016). O Diário de Anne Frank (trad. Alves Calado). Rio de Janeiro: Record. 
Plath, S. (2017). Os diários de Sylvia Plath: 1950-1962 (trad. Celso Nogueira). Rio de Janeiro: Biblioteca Azul.

_ (2019). A redoma de vidro (trad. Chico Mattoso). Rio de Janeiro: Biblioteca Azul.

Smith, P. (2010). Só garotos (trad. Alexandre Barbosa de Souza). São Paulo: Companhia das Letras.

Sontag, S. (2004). Sobre fotografia (trad. Rubens Figueiredo). São Paulo: Companhia das Letras. 